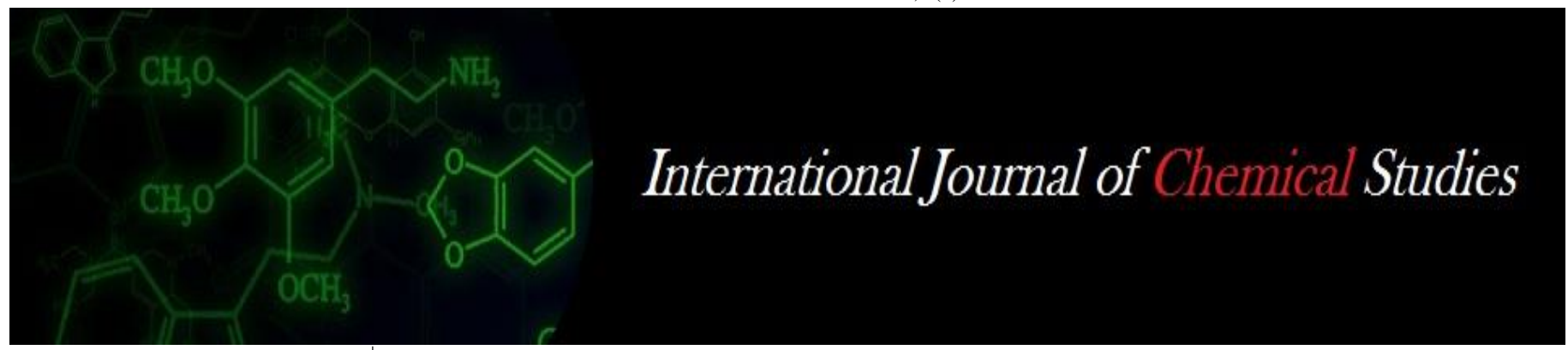

P-ISSN: 2349-8528

E-ISSN: 2321-4902

www.chemijournal.com

IJCS 2020; 8(4): 3774-3777

(C) 2020 IJCS

Received: 01-04-2020

Accepted: 05-05-2020

Pooja Yaddanapudi

Ph. D student, Department of

fruit science, College of

Horticulture- Rajendranagar, Sri

Konda Laxman Telangana state

Horticultural University

Hyderabad, Telangana, India

Kiran Kumar A

Department of Fruit Science,

Associate Dean \& Comptroller of

College of Horticulture,

Rajendranagar, Hyderabad,

Telangana, India

Raja Goud CH

Department of Entomology,

Associate professor $\mathrm{COH}$ -

Rajendranaga, Sri Konda

Laxman Telangana state

Horticultural University

Hyderabad, Telangana, India

Corresponding Author:

Pooja Yaddanapudi

$\mathrm{Ph}$. D student, Department of

fruit science, College of

Horticulture- Rajendranagar, Sri

Konda Laxman Telangana state

Horticultural University

Hyderabad, Telangana, India

\section{Effect of ethylene induced degreening on shelf life of acid lime Cv. Balaji}

\section{Pooja Yaddanapudi, Kiran Kumar A and Raja Goud CH}

DOI: https://doi.org/10.22271/chemi.2020.v8.i4av.10230

\begin{abstract}
Degreening is the process of degradation of chlorophyll by ethylene. High doses of ethylene increase the respiration and shorten shelf life. Hence the present investigation was conducted to identify the best treatment regarding shelf life of Acid lime. Acid lime Cv. Balaji fruits were allowed to degreen in Low Cost Ripening Chamber with ethylene treatment. The investigation concluded that $15 \mathrm{ppm}$ ethylene with 4 pulsings in 24 hours @ 6 hrs. interval followed by 15 ppm ethylene with 2 pulsings in 24 hours @ 12 hrs. interval can be recommended for Acid lime Cv. Balaji for uniform degreening and storage up to sixteen days in normal room temperature.
\end{abstract}

Keywords: Degreening, ethylene, acid lime, Cv. balaji, shelf life

\section{Introduction}

Consumers prefer bright coloured citrus fruit and are willing to pay a premium for them. Green coloured fruits are considered unripe and fetch lower prices. Hence the colour of the rind is important for the aesthetic value and as such it is the most important factor determining marketability. Degreening is the process of degradation of chlorophyll by ethylene. The degreening process is carried out in special rooms designed to treat the fruit with air containing a low concentration of ethylene at controlled temperature and humidity. Despite citrus being a non-climacteric fruit, some aspects of its ripening could be still sensitive to external exposure to ethylene (Sdiri et al, 2012) ${ }^{[1]}$ But high doses of ethylene increase the respiration and shorten shelf life. Hence the present investigation was conducted to identify the best treatment regarding shelf life of Acid lime. Experiment was designated with two factorial completely randomized design and executed with the objective: effect of ethylene induced degreening on shelf life of Acid lime. In the experiment, two factors viz., (A) Ethylene concentrations, (B) Number of pulsings were taken for test. Acid lime Cv. Balaji fruits were allowed to degreen in Low Cost Ripening Chamber with ethylene treatment with different levels of ethylene concentrations i.e. $\left(\mathrm{A}_{1}\right) 5 \mathrm{ppm}\left(\mathrm{A}_{2}\right) 10 \mathrm{ppm}\left(\mathrm{A}_{3}\right) 15 \mathrm{ppm}$ and $\left(\mathrm{A}_{4}\right)$ 20ppm were given four levels of number of pulsings viz., $\left(\mathrm{B}_{1}\right) 6$ pulsings in $24 \mathrm{hrs} @ 4 \mathrm{hrs}$. interval $\left(\mathrm{B}_{2}\right) 4$ pulsings in $24 \mathrm{hrs}$ @ 6 hrs. interval $\left(\mathrm{B}_{3}\right) 2$ pulsings in 24 hrs @ 12 hrs. interval and $\left(\mathrm{B}_{4}\right) 1$ pulsing in 24 hrs @ 24 hrs. interval. . The combination of 2 factors gives 16 treatments viz., $\mathrm{T}_{1}-5 \mathrm{ppm} @ 6$ pulsings in 24 hrs; $\mathrm{T}_{2^{-}}$5ppm @ 4pulsings in $24 \mathrm{hrs} ; \mathrm{T}_{3}-5 \mathrm{ppm} @ 2$ pulsings in $24 \mathrm{hrs}$; $\mathrm{T}_{4^{-}}$5ppm @ 1pulsing in 24 hrs; $\mathrm{T}_{5}-10 \mathrm{ppm} @ 6$ pulsings in $24 \mathrm{hrs}$; $\mathrm{T}_{6}-10 \mathrm{ppm} @ 4$ pulsings in $24 \mathrm{hrs}$; $\mathrm{T}_{7-}$ 10ppm @2pulsings in 24 hrs; $\mathrm{T}_{8}-10 \mathrm{ppm} @ 1$ pulsing in 24 hrs; $\mathrm{T}_{9}-15 \mathrm{ppm} @ 6$ pulsings in 24 hrs; $\mathrm{T}_{10^{-}}$15ppm @ 4pulsings in $24 \mathrm{hrs}$; $\mathrm{T}_{11}-15 \mathrm{ppm} @ 2$ pulsings in $24 \mathrm{hrs} ; \mathrm{T}_{12}-15 \mathrm{ppm} @$ 1pulsing in 24 hrs; $\mathrm{T}_{13}-20 \mathrm{ppm} @ 6$ pulsings in $24 \mathrm{hrs}$; $\mathrm{T}_{14^{-}} 20 \mathrm{ppm} @ 4$ pulsings in $24 \mathrm{hrs}$; $\mathrm{T}_{15^{-}}$ 20ppm@2pulsings in 24 hrs; $\mathrm{T}_{16^{-}}$20ppm @ 1pulsing in 24 hrs.

\section{Materials and Methods}

Acid lime (Citrus aurantifolia S.) Cv. Balaji fruits were collected from citrus orchard. Matured fruits (DA reading-2.02) are harvested manually and immediately transported to degreeening chamber and subjected to the ethylene treatments. Ethylene release canisters named Ripylene, manufactured by chemtron science laboratories, Mumbai were used in the research. 15 grams of ethylene gas was filled in a cylinder with adjustable gauge. This was approved by NHB, FSSAI and FDA as a gas for ripening. The low-cost ripening chamber consists of 40mm PUF (Polyurethane Foam) insulated panels with PPGI Sheets (Pre painted Galvanised Iron) 
lamination on either side, with flashings and swing Door $300 \times 600 \mathrm{~mm}$ with the capacity of 5 crates $(100 \mathrm{~kg})$. The fruits of Acid lime $\mathrm{Cv}$. Balaji were treated with $5 \mathrm{ppm}, 10$ ppm, $15 \mathrm{ppm}$ and $20 \mathrm{ppm}$ of ethylene. In low cost ripening chamber standardization of ethylene gas for different concentrations (5ppm, 10ppm, 15ppm and 20ppm) was carried out on the basis of bubble count (20 bubbles per 10 sec) using ethylene sensor (Table: 1 ).

Spoilage (\%): The number of fruits spoiled in the replication were counted and expressed in percentage. The spoilage determined based on the following visual observations. 1) Shrivelling of the fruit and hardening of the rind. 2) Fungal infection and subsequent rotting.

Spoilage $(\%)=\frac{\text { No. of spoiled fruits in a replication }}{\text { Total no. of fruits in a replication }} \times 100$

Shelf life (days): When more than 50 percent of fruits became unfit for consumption, that stage was considered as the end of shelf life. The number of days taken by the fruits was counted in each treatment and recorded as shelf life.
Table 1: Standardisation of ethylene Dose for degreening of Acid lime (Citrus aurantifolia S.) Cv. Balaji in Low Cost Ripening Chamber.

\begin{tabular}{|c|c|c|}
\hline $\begin{array}{c}\text { Ethylene } \\
\text { dose }\end{array}$ & $\begin{array}{c}\text { No.of } \\
\text { bubbles/10sec }\end{array}$ & $\begin{array}{c}\text { Time of ethylene gas to be } \\
\text { released }\end{array}$ \\
\hline $5 \mathrm{ppm}$ & 20 & $1 \mathrm{~min}$. \\
\hline $10 \mathrm{ppm}$ & 20 & $1.30 \mathrm{sec}$. \\
\hline $15 \mathrm{ppm}$ & 20 & $1.45 \mathrm{sec}$. \\
\hline $20 \mathrm{ppm}$ & 20 & $2 \mathrm{~min}$. \\
\hline
\end{tabular}

\section{Results and Discussion \\ Spoilage (\%)}

The data pertaining Spoilage (\%) of Acid lime Cv. Balaji at ambient temperature as influenced by ethylene concentrations and number of pulsings in table (2) and illustration (1). An increasing trend of spoilage with increased ripeness was observed. This study was similar to results reported by Gupta and Jawandha (2010) ${ }^{[2]}$ for peaches. Ladaniya and Singh (2001) [3] reported that, no difference due to ethylene treatment but spoilage was higher in non-degreened citrus fruits.

Table 2: Spoilage (\%) of Acid lime Cv. Balaji as influenced by ethylene concentrations and number of pulsings per 24 hrs. at ambient temperature during storage days 6-16 $16^{\text {th }}$ day.

\begin{tabular}{|c|c|c|c|c|c|c|c|c|c|c|c|c|}
\hline & $6^{\text {TH }}$ day & $\mathbf{7}^{\text {th }}$ day & $\mathbf{8}^{\text {th }}$ day & $\mathbf{9}^{\text {th }}$ day & $\mathbf{1 0}^{\text {th }}$ day & $\mathbf{1 1}^{\text {th }}$ day & $\mathbf{1 2}^{\text {th }}$ day & $\mathbf{1 3}^{\text {th }}$ day & $\mathbf{1 4}^{\text {tay }}$ & $\mathbf{1 5}^{\text {th }}$ day & $\mathbf{1 6}^{\text {th }}$ day \\
\hline $\mathrm{T}_{1}$ & 5.88 & 10.85 & 20.88 & 37.87 & 52.86 & & & & & & \\
\hline $\mathrm{T}_{2}$ & 5.62 & 10.78 & 20.63 & 37.63 & 52.67 & & & & & & \\
\hline $\mathrm{T}_{3}$ & 5.44 & 10.59 & 19.85 & 36.84 & 51.87 & & & & & & \\
\hline $\mathrm{T}_{4}$ & - & 6.88 & 12.95 & 22.85 & 38.75 & 52.60 & & & & & \\
\hline $\mathrm{T}_{5}$ & - & - & 6.82 & 13.82 & 22.83 & 38.26 & 56.65 & & & & \\
\hline $\mathrm{T}_{6}$ & - & - & 6.64 & 13.65 & 24.68 & 38.17 & 56.44 & & & & \\
\hline $\mathrm{T}_{7}$ & - & 6.83 & 12.88 & 22.27 & 39.64 & 53.68 & & & & & \\
\hline $\mathrm{T}_{8}$ & - & 6.62 & 12.83 & 21.17 & 37.48 & 58.89 & & & & & \\
\hline $\mathrm{T}_{9}$ & - & - & - & - & 6.96 & 13.92 & 23.86 & 39.87 & 56.07 & & \\
\hline $\mathrm{T}_{10}$ & - & - & - & - & - & - & 6.84 & 13.84 & 23.84 & 39.84 & 56.87 \\
\hline $\mathrm{T}_{11}$ & - & - & - & - & - & - & 6.75 & 13.77 & 23.64 & 39.63 & 56.83 \\
\hline $\mathrm{T}_{12}$ & - & - & - & - & - & 6.95 & 13.87 & 23.31 & 39.45 & 56.60 & \\
\hline $\mathrm{T}_{13}$ & 6.83 & 11.82 & 22.48 & 39.86 & 54.83 & & & & & & \\
\hline $\mathrm{T}_{14}$ & 6.62 & 11.68 & 21.67 & 38.63 & 53.67 & & & & & & \\
\hline $\mathrm{T}_{15}$ & - & - & 6.87 & 13.85 & 22.87 & 39.26 & 57.63 & & & & \\
\hline $\mathrm{T}_{16}$ & - & - & 8.19 & 13.67 & 21.85 & 39.23 & 57.25 & & & & \\
\hline
\end{tabular}

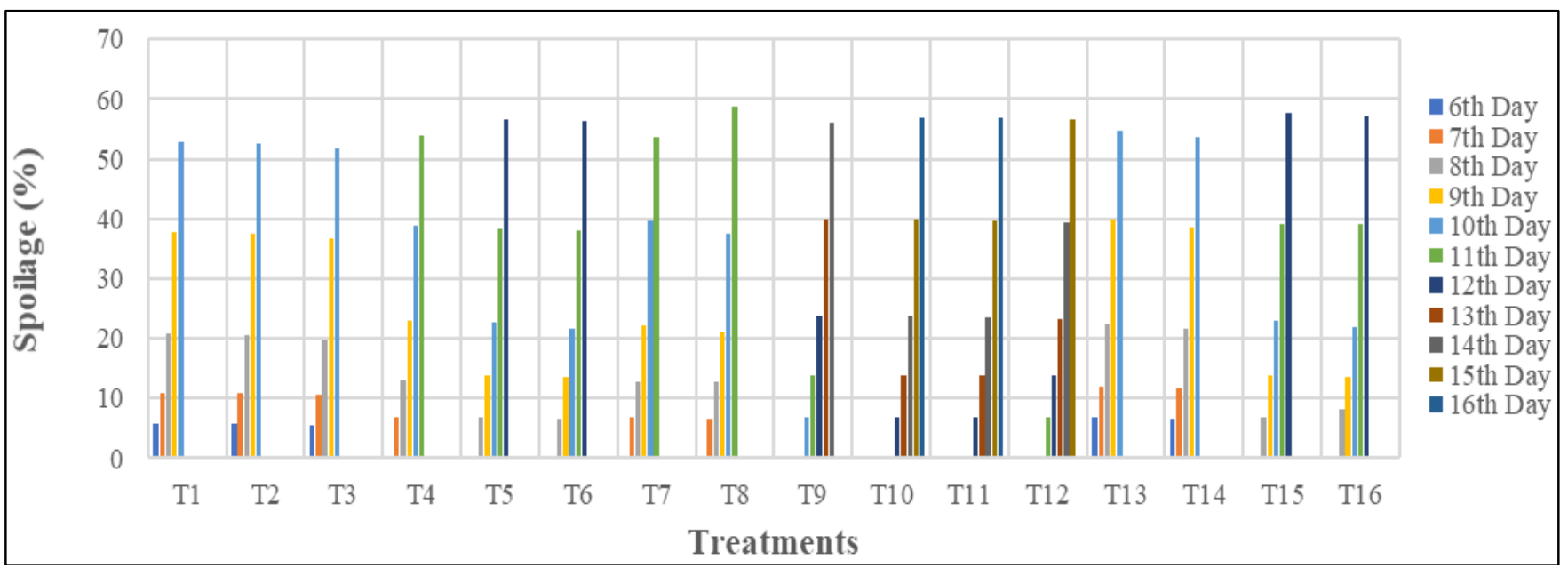

Fig 1: Spoilage (\%) of Acid lime Cv. Balaji as influenced by interaction between ethylene concentrations and number of pulsings per 24 hrs. at ambient temperature on $6^{\text {th }}, 7^{\text {th }}, 8^{\text {th }}, 9^{\text {th }}, 10^{\text {th }}, 11^{\text {th }}, 12^{\text {th }}, 13^{\text {th }}, 14^{\text {th }}, 15^{\text {th }}$ and $16^{\text {th }}$ day.

Shelf life: The data pertaining to shelf life of Acid lime Cv. Balaji at ambient temperature as influenced by ethylene concentrations and number of pulsings in table (3) and illustrations (2 and 3 ). In present investigation, shelf life was diminished with the prolongation of storage at ambient temperatures and decreased with increased in ethylene dose. Nevertheless, besides the beneficial effect in enhancing citrus fruit colour change, exposure to ethylene carries certain 
disadvantages, including acceleration of senescence, button abscission, stem end rot decay and development of physiological disorders leads to reduce the shelf life. Therefore, degreening must be performed under appropriate conditions, using the lowest possible levels of ethylene and shortest possible exposure times (Ron 2008) ${ }^{[4]}$.

Among the ethylene concentrations significantly highest shelf life was noticed with ethylene @ 15 ppm (15.56 days) followed by $10 \mathrm{ppm}$ (11.82 days) while, lowest with $5 \mathrm{ppm}$ (10.53 days). Among the number of pulsings significantly highest shelf life was noticed with 1 pulsing in 24 hrs @ 24 hrs interval (13.04 days) followed by 4 pulsings in 24 hrs @ 6 hrs interval (12.02 days) while, lowest with 6 pulsings in 24 hrs@ 4 hrs interval (11.54 days). 2 pulsings in 24 hrs @ 12 hrs interval (13.02 days) was at par with 1 pulsing in 24 hrs @ $24 \mathrm{hrs}$ interval (13.04 days). According to research data interaction between ethylene concentration and number of pulsings were significantly differed. Highest shelf life was noticed in $15 \mathrm{ppm}$ ethylene with 4 pulsings @ 6 hrs interval (16.45 days) followed by $15 \mathrm{ppm}$ ethylene with 2 pulsings in 24 hrs@12 hrs interval (16.33). 20ppm ethylene with 2 pulsings in 24 hrs @ 12 hrs interval (13.15 days) was at par with 20ppm ethylene with 1 pulsing in 24 hrs @ 24 hrs interval (13.32 days). 10ppm ethylene with 4 pulsings in 24 hrs @ 6 hrs interval (11.20 days) and 10ppm ethylene with 6 pulsings in 24 hrs (11.27 days) was at par with 5ppm ethylene with 2 pulsing in 24 hrs @ 12 hrs interval (11.38 days) while, lowest in 5ppm ethylene with 2 pulsings in 24 hrs @ 12 hrs interval (10.11 days).

Ladaniya and Singh (2001) ${ }^{[3]}$ reported that, in Sweet orange optimum response of degreening was recommended at 5$10 \mathrm{ppm}$ ethylene concentrations, although higher concentrations (100-250) of ethylene treatments increased the rate of post-harvest degreening decay losses. Similar results were reported by Yadava et al (2007) ${ }^{[5]}$, in Sweet orange. The decay loss was significantly affected by ethephon concentration. Rotting during the storage period indicating that, decay loss increases with increase in ethephon concentration.

Rokaya et al. (2016) ${ }^{[6]}$ conducted experiments on shelf life of Mandarin fruits and concluded that, the fruits treated with wax and with Bavistin can be stored up to four weeks at the condition of $14{ }^{\circ} \mathrm{C}-18{ }^{\circ} \mathrm{C}$ temperature and $45 \%-73 \% \mathrm{RH}$.

Table 3: Shelf life of Acid lime Cv. Balaji as influenced by ethylene concentrations and number of pulsings per $24 \mathrm{hrs}$. at ambient temperature

\begin{tabular}{|c|c|c|c|c|c|}
\hline \multirow{2}{*}{ Ethylene concentrations } & \multicolumn{5}{|c|}{ Number of pulsings per $24 \mathrm{hrs}$. } \\
\hline & 6 pulsings & 4 pulsings & 2 pulsings & 1 pulsing & Mean \\
\hline Ethylene@ @ppm & 10.39 & 10.25 & 10.11 & 11.38 & $10.53^{\mathrm{D}}$ \\
\hline Ethylene @ 10ppm & 11.27 & 11.20 & 12.47 & 12.33 & $11.82^{\mathrm{B}}$ \\
\hline Ethylene @ 15ppm & 14.30 & 16.45 & 16.32 & 15.15 & $15.56^{\mathrm{A}}$ \\
\hline Ethylene @ 20ppm & 10.22 & 10.16 & 13.15 & 13.32 & $11.74^{\mathrm{C}}$ \\
\hline Mean & $11.54^{\mathrm{c}}$ & $12.02^{\mathrm{b}}$ & $13.02^{\mathrm{a}}$ & $13.04^{\mathrm{a}}$ & \\
\hline \multicolumn{3}{|l|}{ Factors } & \multicolumn{3}{|c|}{ SEm \pm} \\
\hline \multicolumn{2}{|c|}{ Ethylene concentrations (A) } & 0.09 & \multicolumn{3}{|c|}{0.03} \\
\hline \multicolumn{2}{|c|}{ Number of pulsings (B) } & 0.09 & \multicolumn{3}{|c|}{0.03} \\
\hline \multicolumn{2}{|l|}{ Factor $\mathrm{A} \times \mathrm{B}$} & 0.17 & \multicolumn{3}{|c|}{0.06} \\
\hline
\end{tabular}

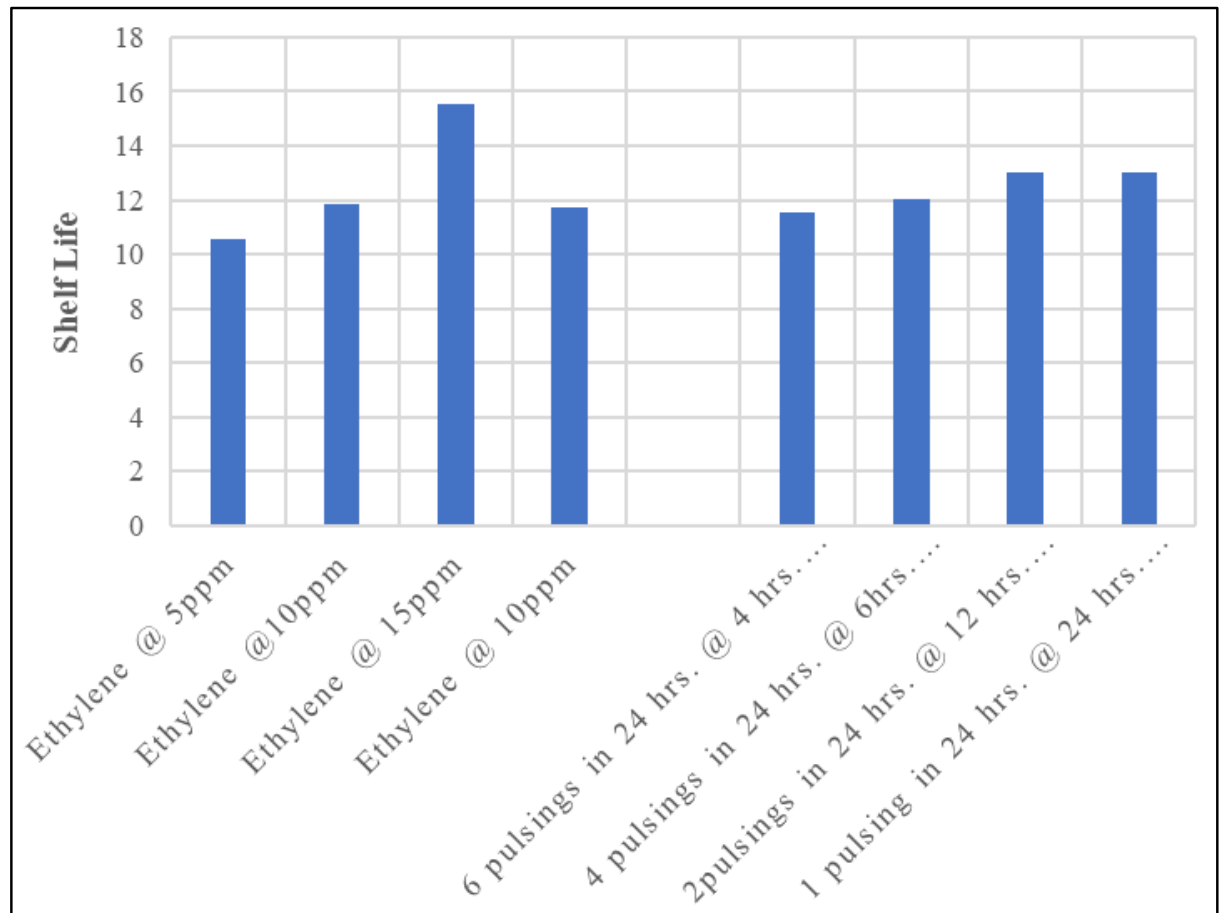

Fig 2: Shelf life (days) of Acid lime Cv. Balaji as influenced by different ethylene concentrations and number of pulsings per 24 hrs. at ambient temperature 


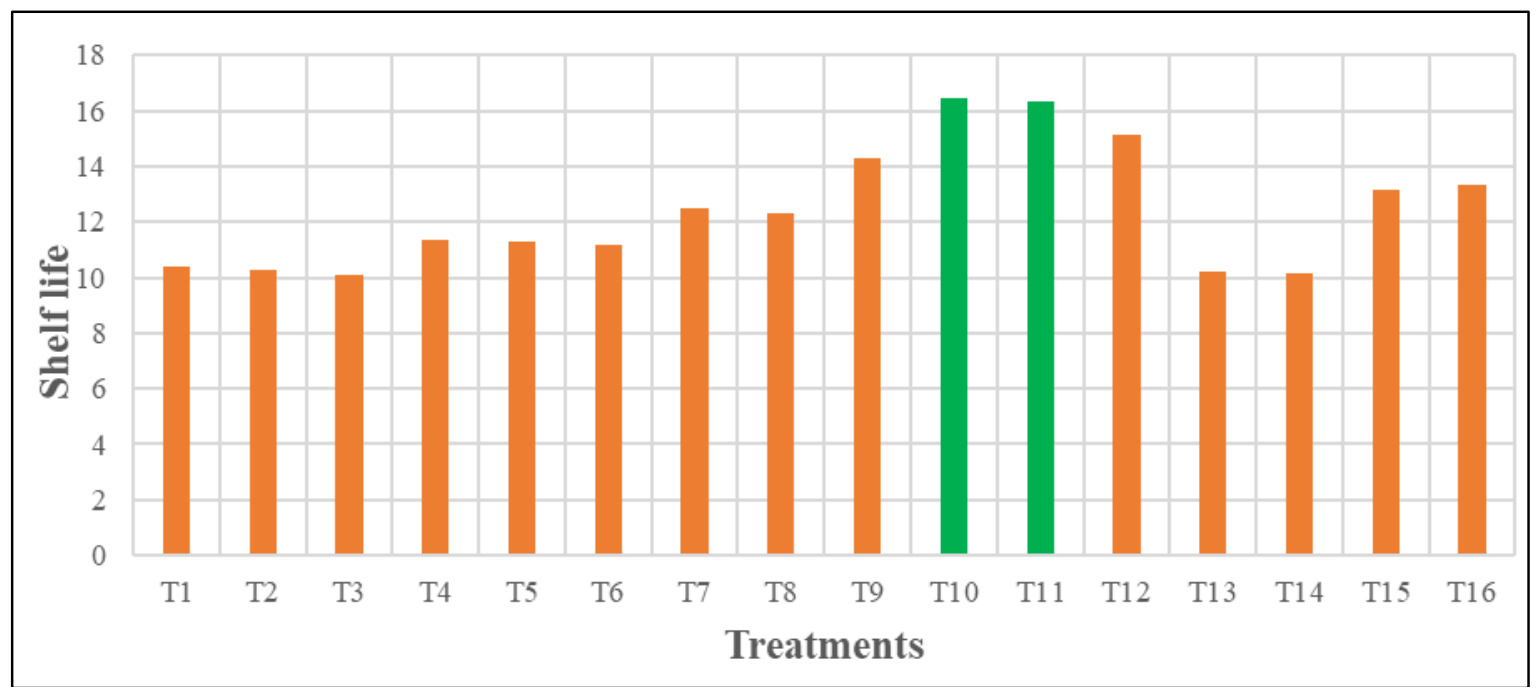

Fig 3: Shelf life (days) of Acid lime Cv. Balaji as influenced by interaction between ethylene concentrations and number of pulsings per 24 hrs. at ambient temperature

\section{Conclusion}

15 ppm ethylene with 4 pulsings in 24 hours @ 6 hrs. interval followed by 15 ppm ethylene with 2 pulsings in 24 hours@ 12 hrs. interval can be recommended for Acid lime Cv. Balaji for uniform degreening and storage up to sixteen days in normal room temperature.

\section{Reference}

1. Sdiri S, Pilar N, Adela M, Jameleddine B, Alejandra S. Effect of postharvest degreening followed by a coldquarantine treatment on vitamin $\mathrm{C}$, phenolic compounds and antioxidant activity of early-season citrus fruit. Postharvest biology and technology. 2012; 65:13-21.

2. Gupta N, Jawandha SK. Influence of maturity stage on fruit quality during storage of Earli Grande peaches. Notulae Scientia Biologicae. 2010; 2(3):96-99.

3. Ladaniya MS, Singh S. Use of ethylene gas for degreening of sweet orange (Citrus sinesis osbeck) cv. Mosambi. Journal of Scientific and Industrial Research 2001; 60:662-667.

4. Ron P. Degreening of Citrus Fruit. A review Tree and Forestry Science and Biotechnology. 2008; 2(1):71-76.

5. Yadava LP, Vijay KG, Rajesh P, Rajeeva G. Post-harvest degreening, storage and quality of Sweet orange (Citrus sinensis Obeck) as influenced by ethephon and carbendazim. A review Asian Journal of Biological Science 2007; 1(3):184-186.

6. Rokaya PR, Dilli RB, Durga MG, Arjun KS, Krishna PP. Effect of postharvest treatments on quality and shelf life of Mandarin (Citrus reticulata Blanco). American Journal of Plant Sciences 2016; 7:1098-1105. 